\title{
Is the Hong Kong Medical Journal having an impact? Impact factor and beyond
}

Ignatius TS Yu, FHKAM (Community Medicine)

Editor-in-Chief, Hong Kong Medical Journal

Hong Kong Med J 2015;21:298

DOI: $10.12809 / \mathrm{hkmj} 154655$

The Hong Kong Medical Journal (HKMJ) has recently received the first official impact factor in the 2014 edition of the Journal Citation Reports in the ISI Web of Knowledge published by Thomson Reuters. We acquired a very modest impact factor of 0.872 , placing us 104 out of 153 journals in the category of 'Medicine, General and Internal'. Cites in 2014 of items published in 2012 and 2013 were 88 and 55 respectively.

The HKMJ was first indexed in MEDLINE in 2000, making articles published known and more accessible to the international medical community. After several years of deliberations by the Editorial Board, the decision was taken to join the Science Citation Index (SCI) and HKMJ was listed in the Science Citation Index Expanded (SCIE) in 2012. Citations of articles published in HKMJ were then systematically tracked. This helps inform us of the frequency with which our papers are cited in the international medical literature, and is considered to reflect the importance and quality of the research work reported in our journal.

Citations are a measurement of the impact of published articles, but they are not the only one. We do not publish for the sake of publication per se, but to have an impact on medical practice. ${ }^{1}$ We also strive to ensure the validity of research results published in HKMJ to attract more citations of our published work. The Editorial Board agreed on a new requirement for original articles submitted after August 2011, in that there should be two highlighted boxed texts: 'New Knowledge Added by This Study' and 'Implications for Clinical Practice or Policy.2 Prior to submission of papers, authors were particularly asked to consider the implications (applications) of their research work on clinical practice or policy, as these would reflect the potential impacts of published research work in the HKMJ on medical practice.

To further enhance the impact of the journal on medical practice, two senior editors, Prof Michael Irwin and Dr TW Wong have been taking the lead in soliciting high-quality reviews and medical practice papers, respectively. We hope that readers will find such papers relevant to their daily practice. The Editorial Board meets on a regular basis to identify papers suitable for continuing medical education (CME) and the Senior Editor Prof PT Cheung is leading efforts to gain the support of authors in the provision of questions and answers for CME. Senior Editors, Dr Albert Chui and Prof Martin Wong, and all members of the Editorial Board have also contributed substantially to improving the quality of papers published in HKMJ. They have invited appropriate reviewers for manuscripts as well as carried out critical reviews. In 2013, we introduced online-first publication of original articles and review papers following satisfactory completion of the review and editing process. ${ }^{3}$ This enables the potential impact of papers to be realised in a timely manner.

Is the HKMJ having an impact? We believe the answer is yes. To further enhance the impact of HKMJ, we would like to call upon the continued support from readers, authors, reviewers, international advisors, and colleagues on the editorial board and in the editorial office to take HKMJ to the next stage.

\section{References}

1. Yu IT. Calling on your continued love and support [editorial]. Hong Kong Med J 2011;17:4.

2. Yu IT. New blood, new initiatives [editorial]. Hong Kong Med J 2011;17:88.

3. Yu IT. From strength to strength [editorial]. Hong Kong Med J 2013;19:100. 